\title{
The Interactions between Food and Drug
}

\section{Monica Butnariu*}

Banat's University of Agricultural Sciences and Veterinary Medicine "Regele Mihai I al Romanei" Timisoara, Romania

\section{Executive Summary}

Interactions between food and drug is defined as an "interaction resulting from a physical, chemical, physiological, pathological and physiological relationship between a drug and a determinable ingredient, a combination of nutrients or food in general nutritional status of the organism".

Pharmacokinetic interactions at: absorption; distribution; transport; metabolism; drug clearance.

Classification drug-food interactions can be achieved by several criteria: their frequency; clinical significance; the mechanism by which are produced; consequence on the body; the pharmacokinetic occurring; level that is distributed. An interaction is considered clinically significant if the answer alters or compromise nutritional status of the body. The clinical consequences of the interaction refer to disruption pharmacokinetics of drugs or nutrients. Drug-nutrient interactions can be evaluated as disturbances in pharmacokinetic and pharmacodynamic action rarely the drug. Drugs and nutrients can influence signal transduction during impacting drug metabolizing enzymes and transporters on receptor-mediated gene expression. It is known that some drugs are used as substrates, inducers and inhibitors of transporters, enzymes of different tissues, the development of direct or indirect interactions with nutrients; these interactions must be known or planned to reduce the impact on the body is produced [1].

After their mode of action, harmful substances are divided into groups:

Anti-nutritive substances whose toxicity is the ability to help reduce digestive use of essential nutrients: goitrogenic substances which act by increasing the body need for iodine; and digestive enzyme inhibitors (antitrypsin factor for vegetables) [2]. Toxic substances in foods which adverse effects cannot be compensated by additional intake of nutrients: compounds that exert toxic effects in the body; their mechanism of action can be explained by a particular reactivity, with a molecular mimicry to hormones, amino acids, etc. in some cases the existence of a genetic field favoring the emergence of a certain pathologies [3]. Substances to enhance catabolic losses, molecules of nutrients useful body are consumed in detoxification processes; but may occur nutritional deficiency: benzoic acid is conjugated with glycine and hippuric acid formed; turn benzoylglucuronic acid; transform in acid under the action of vitamin A and glucuronic acid [4]. Photosensitizing substances, photosensitivity skin rashes in areas exposed to light; photosensitizing molecules of substances, light activated, release oxygen radicals which give the product a potential carcinogen and mutagen increased [5].

- Furocoumarines: psoralen $\left(\mathrm{C}_{11} \mathrm{H}_{6} \mathrm{O}_{3}\right)$, angelicin $\left(\mathrm{C}_{11} \mathrm{H}_{6} \mathrm{O}_{3}\right)$ photosensitizing substances present in parsley, celery, figs, bergamot (orange species);

- Hypericin, present in plants of the genus Hypericum, causes skin manifestations.

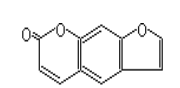

psoralen

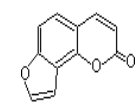

angelicin

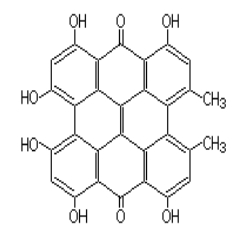

hypericin
Goitrogenic compounds (have goitrogenic and/or antithyroid effects), goitre thyroid gland hyperplasia is a multifactorial etiology, due to a defect in the incorporation of iodine; iodine deficiency in the diet favours the appearance of goitre. Another cause is the presence of different plant favouring food (cruciferous vegetables, other vegetables) of compounds through various biochemical mechanisms; prevent the incorporation of iodine into the thyroid [6]. Two groups are known exogenous substances involved in causing hypothyroidism, through different mechanisms:

- Thiocyanates and isothiocyanates of Brassica species (Brassica campestris and Brassica napus).

- $\quad$ Goitrin and progoitrin of rutabaga (seeds and roots), Brassica campestris and Brassica napus.

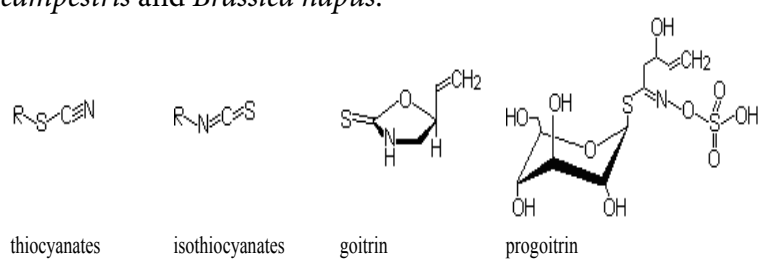

Tio-oxazolidon (progoitrin) is a pronounced antithyroid action tioglucozid; the active ingredient is goitrin. Cabbage has glycosides containing aglycones sprouts which are thiocyanates $(50 \mathrm{mg} /$ $\mathrm{kg})$, isothiocyanate $(100 \mathrm{mg} / \mathrm{kg})$, tiooxazolidina $(10 \mathrm{mg} / \mathrm{kg})$ and anthocyanins. Thiocyanates $(\mathrm{N}=\mathrm{C}-\mathrm{S}-\mathrm{R})$. In enzymatic hydrolysis of tioglucozide (glucubrasicina) is formed thiocyanates goitrogenic effect. Thiocyanate ion is present in body fluids; the human body can synthesize thiocyanate under the action of trans-sulfuraze using sulfur donors, cyanide and nitrites, substances from the decomposition glucosides and tioglucozides cianogenetics. Isothiocyanates (R$\mathrm{N}=\mathrm{C}=\mathrm{S}$ ), the resulting isothiocyanates are produced by enzymatic hydrolysis of the tioglucozidelor; allyl isothiocyanate (allyl mustard

*Corresponding author: Monica Butnariu, Banat's University of Agricultura Sciences and Veterinary Medicine "Regele Mihai I al Romanei" Timisoara, Romania. 300645, Calea Aradului 119, Timis, Romania, Tel: +40-0-256-277; E-mail: monicabutnariu@yahoo.com

Received February 11, 2015; Accepted February 12, 2015; Published February 16, 2015

Citation: Butnariu M (2015) The Interactions between Food and Drug. J Pharmacogenomics Pharmacoproteomics 6: e143. doi:10.4172/2153-0645.1000e143

Copyright: (c) 2015 Butnariu M. This is an open-access article distributed under the terms of the Creative Commons Attribution License, which permits unrestricted use, distribution, and reproduction in any medium, provided the original author and source are credited. 
oil), 3-(Methylsulfonyl)propyl isothiocyanate in cruciferous give rise to goitre in people who ate foods containing them. Cruciferous vegetables are a food source of glucosinolates which are metabolized to isothiocyanate and indoles. These potential interactions are influenced by enzyme polymorphism (isoenzymes of glutathione-S-transferase), insufficiently known and studied. Knowledge of glutathione-Stransferase genotypes is not sufficient to predict interactions of dietary sources of isothiocyanate products. Fruit juices (citrus, apples) may have an influence on the course of drugs in the body based on furanocoumarins and flavonoids. For some juices is just circumstantial evidence of the existence of interactions. For example cranberry juice with diclofenac interactions occur in vitro but not in vivo in healthy subjects. Various substances in foods may interact differently with drugs. An example is the various constituents of grapefruit juice:
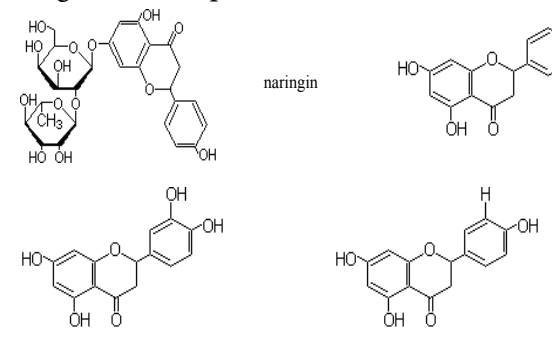

quercetin

kaempferol

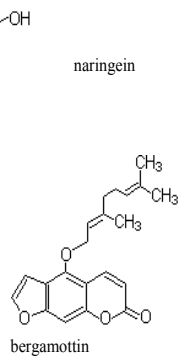

Naringin $\left(\mathrm{C}_{27} \mathrm{H}_{32} \mathrm{O}_{14}\right)$ and naringenin $\left(\mathrm{C}_{15} \mathrm{H}_{12} \mathrm{O}_{5}\right)$ not inhibit CYP3A;

- $\quad$ Furanocoumarins-potently inhibit CYP3A4;

- $\quad$ Quercetin $\left(\mathrm{C}_{15} \mathrm{H}_{10} \mathrm{O}_{7}\right)$ and kaempferol $\left(\mathrm{C}_{15} \mathrm{H}_{10} \mathrm{O}_{6}\right)$ inhibits the formation of estriol by inhibiting CYP3A to catalyze hydroxylation of $17 \beta$-estradiol to estrone, estradiol, etc., what do later form;

- Bergamottin $\left(\mathrm{C}_{21} \mathrm{H}_{22} \mathrm{O}_{4}\right)$ potently inhibits CYP3A4, but not the most important inhibitor of juice.
Although flavonoids such as naringin (naringenin and its aglycone) are important components of grapefruit juice, recent studies suggest that furanocoumarin derivatives such as 6,7-dihydroxybergamottin (furanocoumarin found in grapefruit juice) and bergamottin are strong CYP3A4 inhibitors [7]. Interaction mechanisms citrus fruit juices and fruit smoothie and some vegetables that contain furanocoumarins with drug transporters and metabolizing enzymes are highly controversial.

\section{Conclusion and Recommendation}

Interpretation of the results on drug-food is often difficult and the question is whether the results can be attributed to an interaction of this type or is secondary to nutritional problems. At the molecular level, food is a factor of variability in drug activity. Another problem present in food-drug interactions discussion is direct dependence between the intensity of these interactions and dosage of drugs, which involves additional difficulties because they know that is easy and affordable to calculate the dose of a drug, but for the food, the behaviour of the his or a pollutant is almost impossible to determine a dose, if it can be so.

\section{References}

1. Butnariu M, Caunii $A$ (2013) Design management of functional foods for quality of life improvement. Ann Agric Environ Med. 20: 736-741.

2. Butnariu M, Butu A (2014) Chemical composition of vegetables and their products. Handbook of Food Chemistry 1-49.

3. Ferencz A, Juhász R, Butnariu M, Deér AK, Varga IS, et al. (2012) Expression analysis of heat shock genes in the skin, spleen and blood of common carp (Cyprinus carpio) after cadmium exposure and hypothermia. Acta Biol Hung 63:15-25.

4. Haimi M, Lerner A (2014) Nutritional deficiencies in the pediatric age group in a multicultural developed country, Israel. World J Clin Cases 2:120-125.

5. Butnariu MV, Giuchici CV (2011) The use of some nanoemulsions based on aqueous propolis and lycopene extract in the skin's protective mechanisms against UVA radiation. Journal of Nanobiotechnology 9: 3.

6. Sattarzadeh M, Zlotkin SH (1999) Iron is well absorbed by healthy adults after ingestion of double-fortified (iron and dextran-coated iodine) table salt and urinary iodine excretion is unaffected. J Nutr 129: 117-121.

7. Butnariu M (2014) Detection of the polyphenolic components in Ribes nigrum L. Ann Agric Environ Med 21: 11-4. 